\title{
Transitions between states of magnetotail-ionosphere coupling and the role of solar wind dynamic pressure: the 25 July 2004 interplanetary CME case
}

\author{
P. E. Sandholt ${ }^{1}$, C. J. Farrugia ${ }^{2}$, and W. F. Denig ${ }^{3}$ \\ ${ }^{1}$ Department of Physics, University of Oslo, Oslo, Norway \\ ${ }^{2}$ Space Science Center, University of New Hampshire, Durham, USA \\ ${ }^{3}$ National Geophysical Data Center (NGDC), NOAA, Boulder, Colorado, USA \\ Correspondence to: P. E. Sandholt (p.e.sandholt@ fys.uio.no)
}

Received: 5 December 2014 - Revised: 13 March 2015 - Accepted: 18 March 2015 - Published: 1 April 2015

\begin{abstract}
In a case study, we investigate transitions between fundamental magnetosphere-ionosphere (M-I) coupling modes during storm-time conditions (SYM-H between -100 and $-160 \mathrm{nT}$ ) driven by an interplanetary coronal mass ejection (ICME). We combine observations from the near tail, at geostationary altitude (GOES-10), and electrojet activities across the auroral oval at postnoon-to-dusk and midnight. After an interval of strong westward electrojet (WEJ) activity, a $3 \mathrm{~h}$ long state of attenuated/quenched WEJ activity was initiated by abrupt drops in the solar wind density and dynamic pressure. The attenuated substorm activity consisted of brief phases of magnetic field perturbation and electron flux decrease at GOES-10 near midnight and moderately strong conjugate events of WEJ enhancements at the southern boundary of the oval, as well as a series of very strong eastward electrojet (EEJ) events at dusk, during a phase of enhanced ring current evolution, i.e., enhanced SYM-H deflection within -120 to $-150 \mathrm{nT}$. Each of these M-I coupling events was preceded by poleward boundary intensifications and auroral streamers at higher oval latitudes. We identify this mode of attenuated substorm activity as being due to a magnetotail state characterized by bursty reconnection and bursty bulk flows/dipolarization fronts (multiple current wedgelets) with associated injection dynamo in the near tail, in their braking phase. The latter process is associated with activations of the Bostrøm type II (meridional) current system. A transition to the next state of M-I coupling, when a full substorm expansion took place, was triggered by an abrupt increase of the ICME dynamic pressure from 1 to $5 \mathrm{nPa}$. The brief field deflection events at GOES-10 were then
\end{abstract}

replaced by a $20 \mathrm{~min}$ long interval of extreme field stretching ( $B_{z}$ approaching $5 \mathrm{nT}$ and $B_{x} \approx 100 \mathrm{nT}$ ) followed by a major dipolarization $\left(\Delta B_{z} \approx 100 \mathrm{nT}\right)$. In the ionosphere the latter stage appeared as a "full-size" stepwise poleward expansion of the WEJ. It thus appears that the ICME passage led to fundamentally different M-I coupling states corresponding to different levels of dynamic pressure $\left(P_{\mathrm{dyn}}\right)$ under otherwise very similar ICME conditions. Full WEJ activity, covering a wide latitude range across the auroral oval in the midnight sector, was attenuated by the abrupt dynamic pressure decrease and resumed after the subsequent abrupt increase.

Keywords. Magnetospheric Physics (Storms and substorms)

\section{Introduction}

Substorms represent a characteristic cyclical behavior of the magnetosphere-ionosphere system evolving in three phases referred to as growth, expansion, and recovery (Sergeev et al., 2012; Akasofu, 2013). The growth phase is characterized by loading of open magnetic flux in the magnetotail lobes driven by dayside (magnetopause) reconnection. This phase is manifested as thinning of the plasma sheet and strengthening of the cross-tail current, stretching of the tail field, and associated equatorward expansion of the auroral oval and auroral arcs therein. The onset of the expansion phase is characterized by a sudden disruption (reduction) of the cross-tail current and the formation of the substorm current wedge (SCW) (McPherron et al., 1973) leading to en- 
hancements of the westward electrojet (WEJ) in the auroral ionosphere around midnight. The spatial-temporal evolution of SCW is reflected in the corresponding expansion of the WEJ. The cyclical behavior is closed by return (recovery) to the initial state of loading of magnetic energy in the tail lobes, after the episode of enhanced energy dissipation in the auroral ionosphere. The substorm activity may be described in terms of activations of basic current systems in the magnetosphere-ionosphere system consisting of outer and inner loops (Sergeev et al., 2014). The basic elements of the two-loop current system of magnetosphere-ionosphere (M-I) coupling and their relation to auroral electrojets were identified in the early phase of substorm research (Bostrøm, 1964, 1967; McPherron et al., 1973; Yasuhara et al., 1975; Bostrøm, 1977). In this study we shall demonstrate the association between different variants of temporal-spatial structure of these current loops and corresponding variants of auroral electrojet activity related to transitions between different external (solar wind) and internal (ring current) magnetospheric conditions.

Depending on the external (solar wind) conditions, the substorm cycle can appear as an isolated event or as a series of cyclical events. During extreme external conditions, such as during Earth passage of geoeffective interplanetary coronal mass ejections (ICMEs), specific variants of substorm activity appear. In this paper we are restricted to substorm activities occurring during long intervals of continuously strong forcing by ICMEs leading to major storm evolution (SYM-H index $<-100 \mathrm{nT}$ ). According to Kamide et al. (1998) "the storm-substorm relationship is poorly understood, and some of the basic questions remain unsolved regarding the importance of frequently occurring intense substorms in a geomagnetic storm.” One event category is characterized by cycles of field stretching and dipolarization with corresponding particle flux decreases and enhancements at geostationary altitude recurring at $2-3 \mathrm{~h}$ intervals. This variant is referred to as a "sawtooth" event (e.g., Henderson et al., 2006). These events show the presence of a large-scale substorm current wedge (SCW; wide MLT extent) and associated WEJ activity expanding east-to-west and poleward (Sandholt and Farrugia, 2014). Another variant of storm-time repetitive substorm activity consists of multiple current wedgelets associated with Earthward-moving dipolarization fronts (DFs)bursty bulk flows (BBFs). These events (wedgelets) are manifest in the ionosphere as brief electrojet enhancements appearing in both the northern and southern sections of the auroral oval configuration, corresponding to activations of the outer and inner current loops in the plasma sheet (PS) partial ring current (PRC) system (Sandholt et al., 2014). They typically recur at $20-40 \mathrm{~min}$ intervals. Thus, it appears that different variants of M-I coupling appear during the conditions of continuously strong forcing by ICMEs, depending on the dynamic pressure conditions. In order to shed light on the reasons for this multi-state behavior of the PS-PRC system, we selected a case during which we identified clear transi- tions between different modes. The transitions in M-I coupling mode are discussed in relation to external conditions measured by parameters like $E_{\mathrm{KL}}$ (magnetopause merging rate; Kan and Lee, 1979) and the solar wind dynamic pressure $\left(P_{\text {dyn }}\right)$, as well as internal conditions such as represented by the ring current index SYM-H. This is done considering the background of the previous experience that "the inner magnetosphere processes during storms are shown to be a result of a complex interplay of processes at the magnetopause and in the magnetotail in response to solar wind driving" (Pulkkinen et al., 2007). It is recognized that the magnetospheric current system has two types of response to external driving: "one is associated with variations of the solar wind dynamic pressure, rapidly propagating via Alfven waves inside the magnetosphere. The second response is associated with slower processes such as magnetopause merging, plasma convection, particle losses due to pitch angle diffusion, charge exchange etc." (Tsyganenko, 2013). According to Lyons et al. (2005), a $P_{\mathrm{dyn}}$ enhancement under strongly southward interplanetary magnetic field (IMF) conditions "is found to cause both compressive auroral brightening away from the bulge region and a Harang-region substorm auroral brightening" - leading to a very broad auroral enhancement covering $\sim 10-15 \mathrm{~h}$ of MLT.

Essential to the question of different M-I coupling modes during storm-time substorm activity is the stability of the near-Earth neutral line (NENL) and the presence of largescale SCW versus chaotic magnetotail reconnection and resulting smaller-scale (azimuthal) wedgelets depending on the ring current evolution (see Noah and Burke (2014) and references therein). By our approach of distinguishing between auroral electrojet responses in different latitude and longitude regimes of the auroral oval, i.e., the oval south and north regimes at midnight and dusk, we are able to identify different elements of the substorm current system. On the duskside distinction between the oval north and oval south activities, we refer to combined ground and Defense Meteorological Satellite Program (DMSP) F13 observations reported in a recent case study (Sandholt et al., 2014).

Central to our analysis is the discussion of ground-satellite conjunction data in the context of the two-loop model of the SCW. This model is characterized by (i) an outer loop connecting the cross-tail current disruption and corresponding electrojet activity in the northern part of the auroral oval (the Bostrøm type I azimuthal loop) and (ii) an inner loop connecting the near tail (PRC) and the southern part of the oval by Bostrøm type II current systems (meridional loops) maximizing at dusk and post-midnight MLTs. Our focus on the closure currents in the northern and southern sections of the auroral oval (Sandholt et al., 2014) represents an extension of the two-loop model of Sergeev et al. (2014) (see also Yang et al., 2012 and Birn and Hesse, 2014). Activations of the inner loop, which we refer to as Bostrøm type II, in the phase of plasma braking and diversion in the near tail during plasma intrusion events (Earthward-moving BBFs; see Baumjohann 
et al., 1990), are described in, e.g., Yang et al. (2012) and Birn and Hesse (2014).

In companion papers, we use a ground-satellite DMSP F13 data combination to identify outer and inner loop activities with their associated manifestations across the auroral oval at dusk (Sandholt et al., 2014). We utilize data from a second ICME case (18 August 2003) showing very similar interplanetary (IP) conditions as in the present case $(25$ July 2004), when Geotail satellite observations of Earthwardmoving BBFs and dipolarization fronts (DFs) (Nakamura et al., 2002; Runov et al., 2011) at $\mathrm{X}=-11 R_{\mathrm{E}}$ in combination with GOES-10 observations closer to Earth were available. By that approach we identified outer loop manifestations in the magnetosphere (BBFs/DFs) and ionospheric signatures such as poleward boundary intensifications (PBIs; see Lyons et al., 1999) and multiple auroral streamers and streamer convection channels in the northern oval regime. These events were preceded by brief polar cap convection (PCN) enhancements indicating a relationship with bursts of tail reconnection (Sergeev et al., 2012). The inner loop activations at GOES-10 (geostationary altitude; 04:00-06:00 MLT) were characterized by brief field deflection events ( $B_{\mathrm{tot}}$ increase; $B_{x}$ decrease, $B_{y}$ increase, $B_{z}$ increase) and associated electron flux decrease. The field deflections, dominated by strong $B_{y}$ increases, were attributed to Bostrøm type II current sheet activations, with associated WEJ events in the oval south regime (near-equatorward boundary) at midnight and postmidnight MLTs.

In the present paper, we study ground-satellite conjunction observations of the inner loop activity during the attenuated WEJ activity observed within intervals of low $P_{\mathrm{dyn}}$ conditions. We find that the M-I coupling in this case is characterized by (i) reduced amplitude of the AL index deflections, (ii) the absence or attenuation of the phase of poleward expansion of the WEJ, and (iii) a corresponding absence of major dipolarization in the near-tail magnetosphere. It may therefore be referred to as a moderate (attenuated) substorm activity. We investigate the external (ICME) and internal (SYM-H index) conditions leading to this specific mode of M-I coupling by identification of transitions between the state of attenuated activity and the full (major) substorm (electrojet) activation. The latter is identified by a major magnetic field dipolarization $\left(B_{z}\right.$ increase and $B_{x}$ decrease) at geostationary altitude and associated stepwise poleward expansion of the westward electrojet (Alaska chain magnetograms), which appeared abruptly after a $20 \mathrm{~min}$ long interval of extreme field stretching, as measured by GOES10. An external (solar wind) trigger for this transition in the state of M-I coupling is identified.

Thus, we shall emphasize the presence of two very different M-I coupling states (attenuated/quenched substorm activity versus full substorm expansion) which are characterized by (i) repetitive events of magnetic field deflection $\left(\triangle B_{z}<0\right.$; $\Delta B_{y}>0 ; \Delta B_{x}>0$ ) at geostationary altitude (near midnight), with corresponding strong activations of the inner cur-

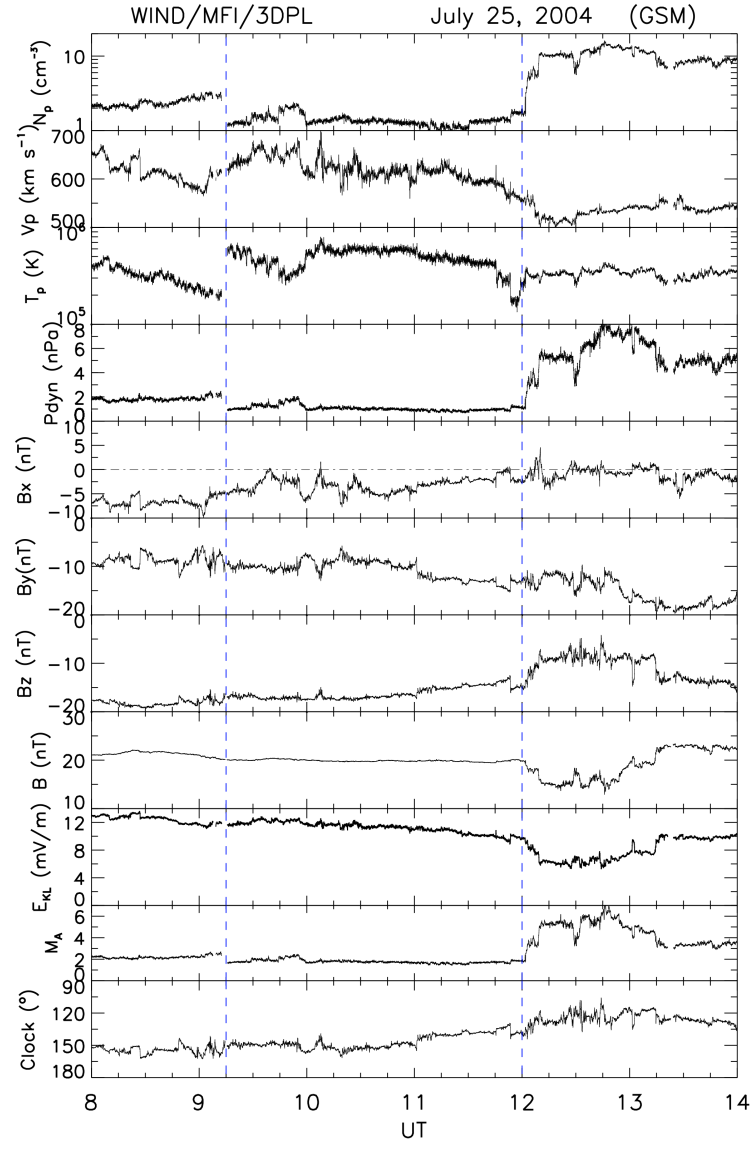

Figure 1. Wind satellite data during the interval 08:00-14:00 UT. Panels from top to bottom show proton density $\left(N_{\mathrm{p}} ; \mathrm{cm}^{-3}\right)$, bulk speed $\left(V_{\mathrm{p}} ; \mathrm{km} \mathrm{s}^{-1}\right)$, proton temperature $T_{\mathrm{p}}(\mathrm{K})$, dynamic pressure (nPa), magnetic field components $B_{x}, B_{y}$, and $B_{z}(\mathrm{nT})$ in GSM coordinates, the total field strength $(B)$, the Kan-Lee merging electric field, $E_{\mathrm{KL}}\left(\mathrm{mV} \mathrm{m}^{-1}\right)$, the Alfvén-Mach number $(M a)$, and the clock angle of the magnetic field (polar angle in GSM $y-z$ plane). Vertical guidelines mark the drop of $P_{\mathrm{dyn}}$ at 09:15 UT and subsequent increase at 12:00 UT.

rent loop connecting the PRC and eastward/westward electrojets at the auroral oval equatorward boundary (Bostrøm type II current system) and (ii) intervals of more extreme field stretching $\left(B_{z}=5 \mathrm{nT} ; B_{x}=100 \mathrm{nT}\right)$ in the near tail leading to large-scale current disruption (outer loop) and associated stepwise poleward expansion of the westward electrojet in the northern part of the oval at night. We investigate the role of solar wind dynamic pressure for transitions between these M-I coupling modes in the context of ICME geoeffectiveness involving electrojet activities at dusk and midnight and the ring current evolution as monitored by the SYM-H index. 


\section{Data description}

Figure 1 shows interplanetary (IP) data from the Wind satellite during the interval 08:00-14:00 UT when an interplanetary CME passed the spacecraft. The average Wind location was $(261,5,18) R_{\mathrm{E}}$ (GSE coordinates). We note the smooth variations of all ICME parameters with two exceptions for the discontinuities in plasma density and dynamic pressure occurring at 09:15 and 12:00 UT. The magnetic field is large and southwest directed $\left(B_{x}<0 ; B_{z}<0\right)$ for many hours, giving rise to persistent strong forcing of the Earth's magnetosphere, i.e., $E_{\mathrm{KL}}=6-12 \mathrm{mV} \mathrm{m}^{-1}$. Two vertical guidelines mark drops of the solar wind density (from 3 to $\left.1 \mathrm{~cm}^{-3}\right)$ and dynamic pressure $P_{\mathrm{dyn}}$ from 2 to $1 \mathrm{nPa}$ at 09:15 UT and the subsequent increases $\left(P_{\mathrm{dyn}}\right.$ increase from 1 to $5 \mathrm{nPa}$ ) near 12:00 UT. The solar wind bulk speed fluctuates between 500 and $650 \mathrm{~km} \mathrm{~s}^{-1}$. We note a slight decrease of the speed from 560 to $510 \mathrm{~km} \mathrm{~s}^{-1}$ around the density discontinuity at 12:00 UT. The $B_{x}$ component is slightly negative; $B_{y}$ and $B_{z}$ are both strongly negative ( -10 to $-20 \mathrm{nT}$ ). The $E_{\mathrm{KL}}$ index decreases slowly from 12 to $10 \mathrm{mV} \mathrm{m}^{-1}$ in the interval 09:15-12:00 UT. Then we note a faster $E_{\mathrm{KL}}$ decrease from 10 to $6 \mathrm{mV} \mathrm{m}^{-1}$ at 12:00-12:10 UT. The clock angle increases smoothly from 160 early in the interval and lies within $135-120^{\circ}$ during 12:00-13:00 UT.

In this study we shall focus on magnetospheric substorm activity associated with (i) the interval of stable ICME conditions (extraordinary smooth and strong $\mathrm{B}$ and very low density; small Alfvén-Mach number $M a$ ) with reduced $P_{\mathrm{dyn}}$ ( $=1 \mathrm{nPa}$ ) from 09:15 to 12:00 UT and (ii) the response to the enhanced $P_{\text {dyn }}(=5 \mathrm{nPa})$ observed from 12:00 UT onwards.

Figure 2 shows magnetic field and particle flux data obtained from spacecraft GOES-10 during the interval 10:0014:00 UT, as it traversed the 01:00 to 05:00 MLT sector. Magnetic field perturbation events accompanied by electron flux decreases (increases) are marked by vertical guidelines. Events in the interval 10:00-13:25 UT are of a similar nature: $B_{x}$ increase; $B_{y}$ increase, $B_{z}$ decrease and $B_{\text {tot }}$ increase. These are brief events of field stretching $\left(B_{z}\right.$ dips to $\left.\sim 10 \mathrm{nT}\right)$ and strengthening. They are accompanied by electron flux decreases.

Then a phase of extreme field stretching appears during the interval 13:20-13:30 UT characterized by a $B_{z}$ decrease from 20 to $5 \mathrm{nT}$ and a $B_{x}$ increase to $100 \mathrm{nT}$. This is followed by a gradual, strong dipolarization ( $B_{z}$ increase, $B_{\text {tot }}$ increase, $B_{y}$ increase) during 13:40-13:50 UT and a further major dipolarization ( $B_{z}$ increase, $B_{x}$ decrease, $B_{y}$ decrease, $B_{\text {tot }}$ decrease) during 13:50-14:00 UT. The latter is accompanied by electron flux increase.

Below we shall identify corresponding signatures in the auroral oval electrojet activity around midnight, as measured by Alaska chain magnetometer data.

Figure 3 shows Alaska chain $\mathrm{H}$ component magnetograms for the interval 08:00-16:00 UT. The traces are ordered from lower (top panel) to higher magnetic latitudes in the range

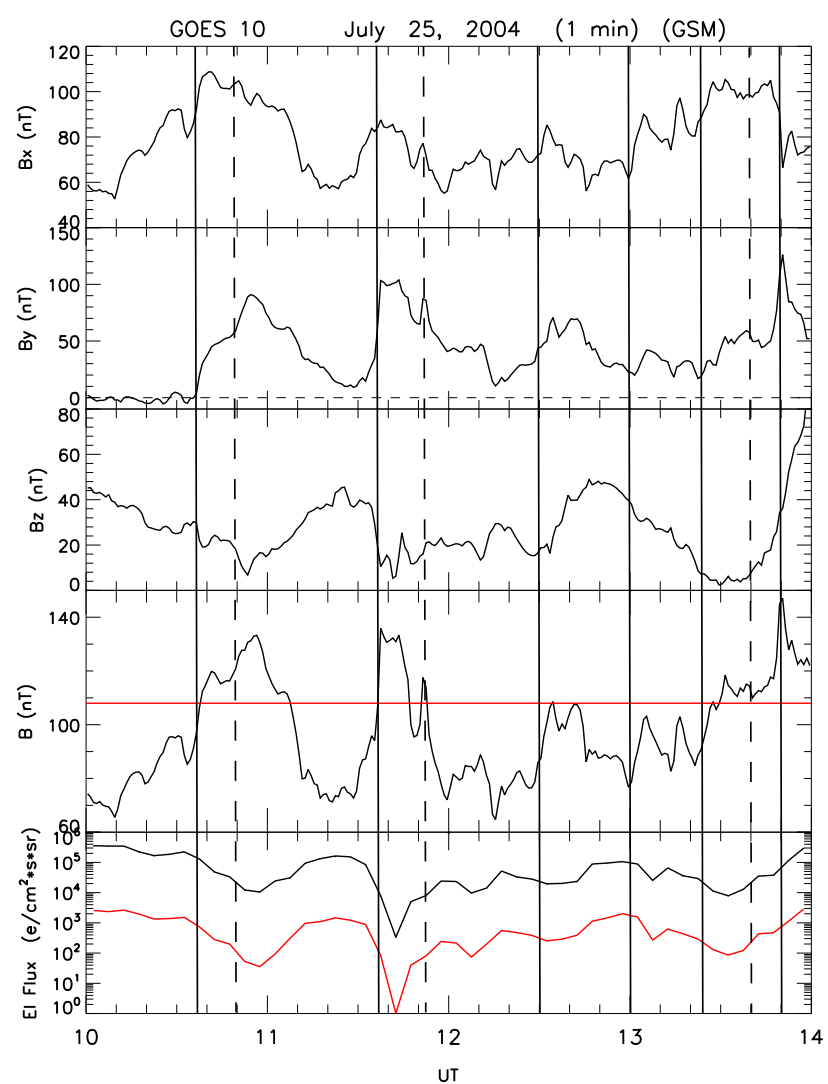

Figure 2. GOES-10 data during the interval 10:00-14:00 UT. Panels from top to bottom show the magnetic field components $B_{x}$, $B_{y}, B_{z}$, the total field $\mathrm{B}$, and (bottom) electron fluxes in black $(>0.6 \mathrm{MeV})$ and red $(>2 \mathrm{MeV})$ traces. Vertical guidelines mark changes in field orientation and magnitude accompanied by electron flux decreases (increases). See text for details.

of $63.6^{\circ}$ (Gakona) to $68.7^{\circ}$ MLAT (Arctic Village). The vertical guidelines at 09:52 and 13:40 UT delimitate an interval of moderate (attenuated) electrojet activity compared to the intervals before and after. The interval before 09:52 UT is characterized by a series of strong electrojet activations spanning the whole MLAT range covered by these stations. Then from 09:52 UT onwards, a series of more moderate electrojet activation are marked by the dashed lines. This activity maximizes at the lower latitude stations Gakona (63.6 MLAT) and CIGO $\left(65.4^{\circ} \mathrm{MLAT}\right)$. Unlike the previous events, 4 the CIGO activation at 13:40 UT is followed by a stepwise poleward expansion as manifested by the abrupt deflections at Ft. Yukon (green; $67.4^{\circ}$ MLAT) and Arctic Village (black bottom trace; $68.7^{\circ}$ MLAT) at 13:45 and 13:50 UT (see tilted arrows), respectively. The latter event of poleward expansion in the interval 13:40-14:00 UT corresponds to the event of major field dipolarization after the extreme field stretching, as detected by the spacecraft GOES-10.

The events of more moderate electrojet activity in the interval 10:00-13:30 UT (dashed lines) correspond to events of 


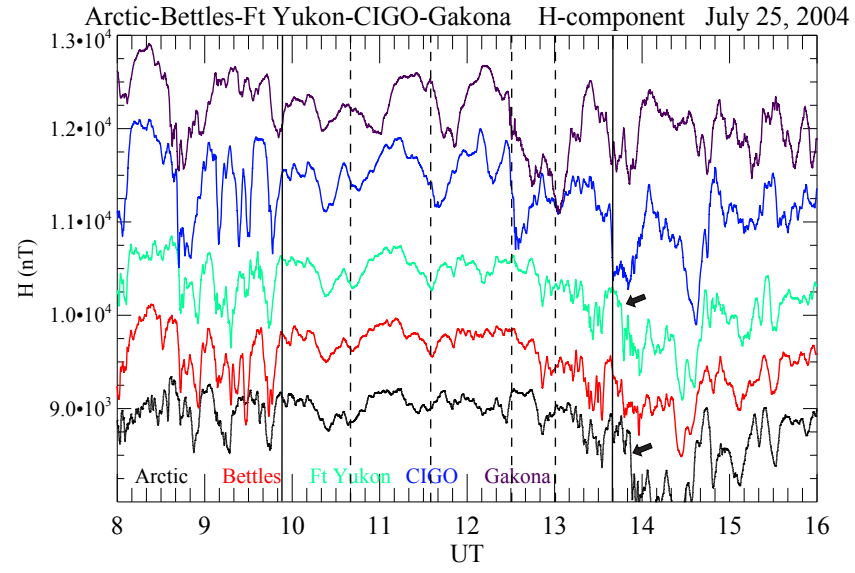

Figure 3. Alaska chain magnetograms during the interval 08:0016:00 UT. Panels from top to bottom show $\mathrm{H}$ component magnetograms at stations ordered by increasing magnetic latitude from top to bottom: Gakona (top; $63.6^{\circ}$ MLAT), CIGO (65.4 ${ }^{\circ}$ MLAT), Ft. Yukon (67.4 $4^{\circ}$ MLAT), Bettles, and Arctic Village (bottom; 68. $7^{\circ}$ MLAT). Vertical guidelines at 10:00 and 13:30 UT delimitate a period of moderate (attenuated) electrojet activity compared to the periods before and after. The stepwise poleward expansion of the auroral electrojet at 13:45 and 13:50 UT is marked by the tilted bold arrows.

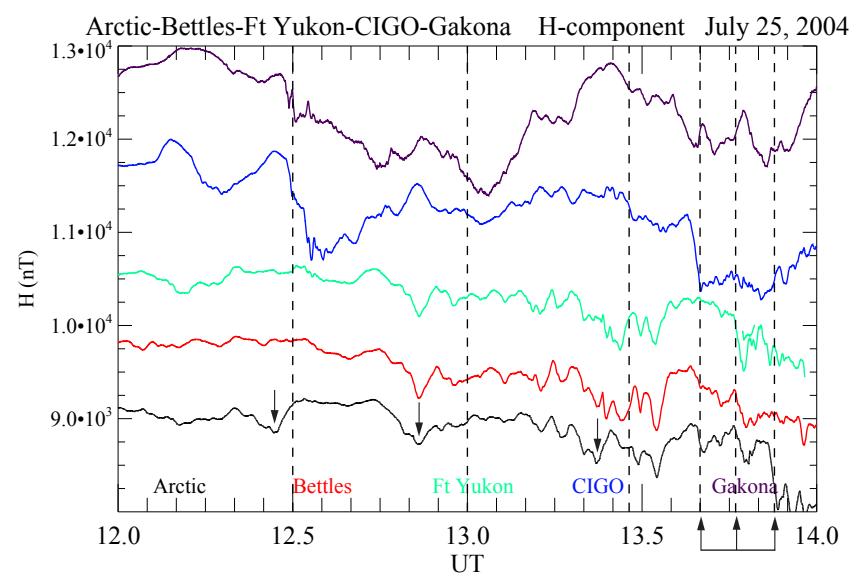

Figure 4. Alaska chain magnetograms during the interval 12:0014:00 UT. Panels from top to bottom show $\mathrm{H}$ component magnetograms from stations ordered by increasing magnetic latitude: Gakona (top; $63.6^{\circ}$ MLAT), CIGO (65.4 ${ }^{\circ}$ MLAT), Ft. Yukon $\left(67.4^{\circ} \mathrm{MLAT}\right)$, Bettles, and Arctic Village (68.7 ${ }^{\circ}$ MLAT; bottom panel).

brief field stretching $\left(\Delta B_{z}<0 ; \Delta B_{y}>0 ; \Delta B_{x}>0\right)$ at geostationary altitude, as marked by guidelines in Fig. 2 .

Figure 4 shows an expanded view of the electrojet activity during the interval 12:00-14:00 UT. The events at 12:30, 13:00, and 13:25 UT, maximizing at stations CIGO (blue) and Gakona (violet), are marked by dashed guidelines. These events are preceded by deflections at the northernmost station Arctic Village (see arrows in bottom panel). They are

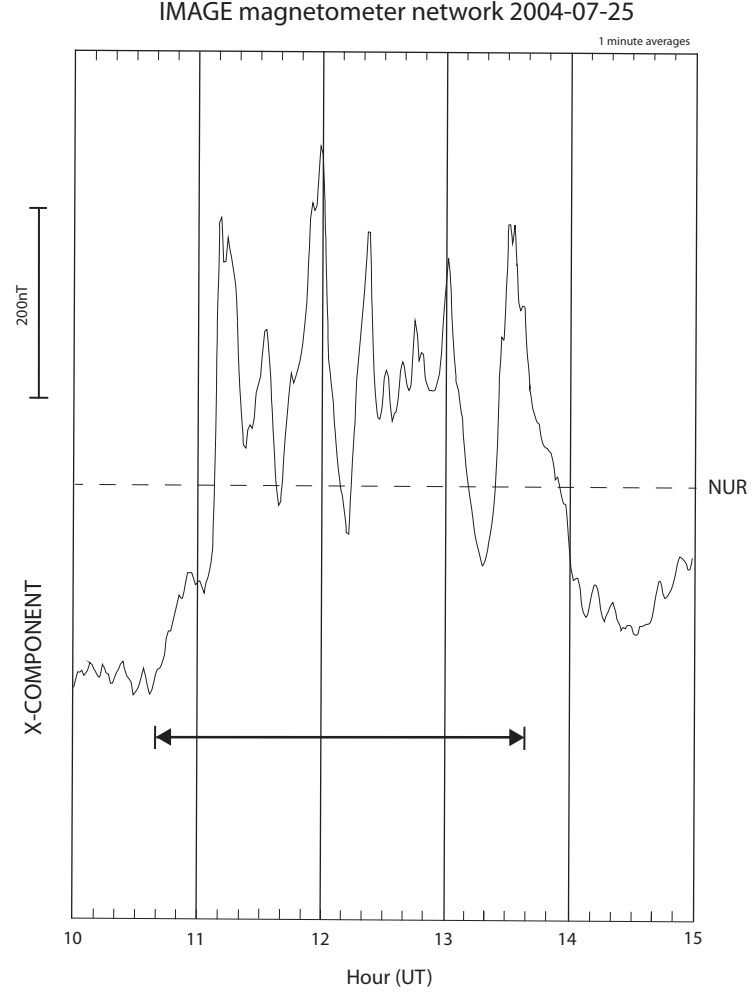

Figure 5. IMAGE chain $H$ component magnetogram from station NUR (56.9 ${ }^{\circ}$ MLAT) during the interval 10:00-15:00 UT.

interpreted as electrojet activations associated with the wellknown phenomenon of poleward boundary intensifications (PBIs; see, e.g., Lyons et al., 1999 and Sandholt et al., 2002). They typically appear 5-10 min before the corresponding activations at the lower-latitude stations Gakona-CIGO. The interval 13:30-14:00 UT is dominated by the multiple electrojet activations at 13:40, 13:46, and 13:53 UT (marked by arrows at the bottom line), each of which represents a progression to higher latitude.

Figure 5 shows an IMAGE $\mathrm{H}$ component magnetogram from station NUR $\left(56.9^{\circ} \mathrm{MLAT}\right)$ during the interval 10:00-15:00 UT when this station traversed the $\sim 13: 30$ 18:30 MLT sector. Positive H deflections at NUR, representing the oval equatorward boundary, are manifestations of a series of activations of the Bostrøm type II current system during the interval 10:40-13:40 UT. From $\sim 10: 40$ UT ( $\sim$ 14:00 MLT) onwards, station NUR is sensitive to strong eastward electrojet (EEJ) events originating in nightside substorm activity. The series of EEJ events came to a halt at 13:30 UT. We note that the strongest EEJ events in the interval 10:30-13:30 UT recur at a similar rate as the WEJ events observed near midnight from Alaska stations (see Fig. 3).

Figure 6 shows the geomagnetic indices AL (nT) and SYM-H (nT) for the interval 08:00-16:00 UT. AL represents the westward electrojet activity while SYM-H is a ring current index. We note the presence of reduced (attenuated) AL 


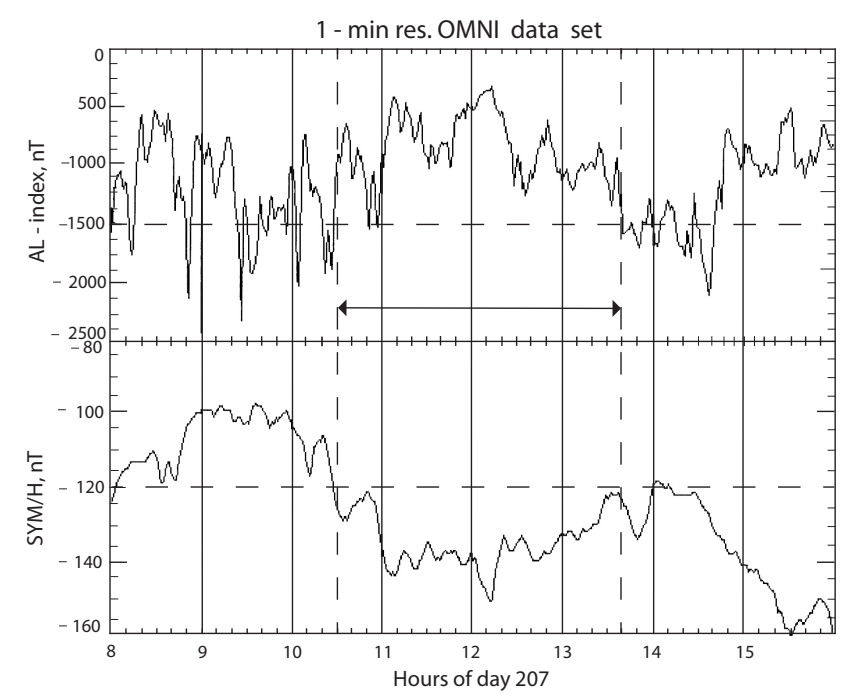

Figure 6. Geomagnetic indices AL (nT) and SYM-H (nT) for the interval 08:00-16:00 UT on 25 July 2004. The attenuated substorm activity (reduced AL deflection peaks) during the interval 10:3013:40 UT is marked by vertical guidelines and horizontal doublearrowed line.

activity in the interval 10:30-13:40 UT. In fact, AL deflection maxima decrease to $-1000 \mathrm{nT}$ in the interval 11:0013:40 UT. This is contrary to the activities before and after when AL deflections approach $-2000 \mathrm{nT}$. The attenuated AL deflections in the actual interval are accompanied by enhanced SYM-H deflections within the range of -130 to $-150 \mathrm{nT}$. Referring back to the IMAGE data in Fig. 5, we note that the interval of attenuated WEJ and enhanced SYM-H deflection is characterized by enhanced EEJ activity at dusk.

Figure 7 shows cross-track ion drift measurements along the DMSP F13 track from dusk to dawn and schematic mapping of field-aligned current systems between the southern $(\mathrm{S})$ and northern $(\mathrm{N})$ parts of auroral ionosphere and magnetosphere at dusk and midnight. Approximate fields of view of magnetometer chains in Scandinavia (IMAGE) and Alaska at 10:40 UT are marked by double-arrowed meridional lines. The two current systems are closed by azimuthal and meridional currents in the ionosphere and are therefore often referred to as the azimuthal and meridional loops, or as Bostrøm types I and II current systems (Bostrøm, 1967, 1977).

The M-I coupling illustrated in the figure represents the interval of attenuated substorm activity (10:30-13:40 UT), characterized by multiple PS current wedgelets, as indicated. The relationship with electrojet activities in the northern $(\mathrm{N})$ and southern $(\mathrm{S})$ parts of the auroral oval are shown. Northern part of the oval $(\mathrm{N})$ is characterized by PBIs, auroral streamers, and corresponding streamer convection channels (enhanced anti-sunward convection measured by DMSP F13). The southern part of the oval (S) shows a channel of en-

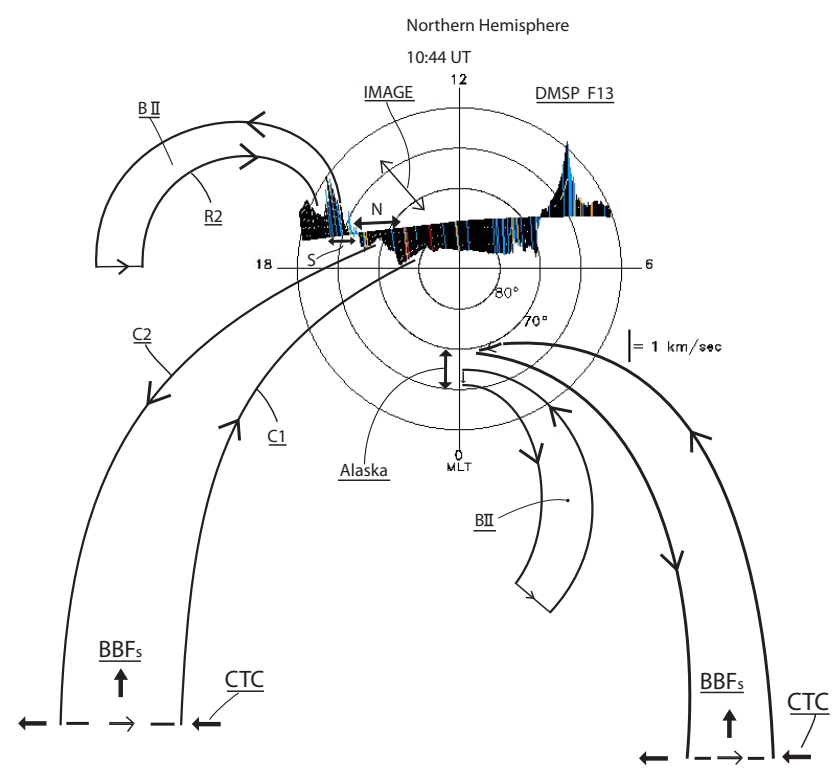

Figure 7. Cross-track ion drift measurements along the DMSP F13 track from dusk to dawn and schematic representation of fieldaligned currents (not to scale) between the auroral ionosphere and the magnetosphere at dusk $(\mathrm{C} 1, \mathrm{C} 2, \mathrm{R} 2)$ and near midnight. The satellite crossings of the southern $(\mathrm{S})$ and northern $(\mathrm{N})$ sections of the double oval configuration at dusk is marked. M-I coupling via Bostrøm type I and II current systems in the oval north and oval south regimes, respectively, is schematically illustrated at dusk and midnight. Connections between bursty bulk flows (BBFs) and crosstail current (CTC) disruptions and oval north regimes are indicated. Approximate fields of view of magnetometer chains in Scandinavia (IMAGE) and Alaska at 10:40 UT are marked by double-arrowed meridional lines. MLAT circles at 50, 60, 70, and $80^{\circ}$ are shown.

hanced sunward flow and bipolar current sheets at its boundaries, as indicated in the figure. This system of field-aligned currents and flow channel give rise to the eastward electrojet at dusk. A series of activations of this system (Bostrøm type II; marked BII in the figure) leads to a corresponding series of strong, positive $\mathrm{H}$ deflections as documented by the IMAGE chain of magnetometers during the interval 10:30-13:30 UT (Fig. 5). Thus, the figure illustrates a system of outer and inner current loops in the PS-PRC system, which are connected to different electrojet activities in the northern and southern parts of the auroral oval. Referring back to Fig. 4 we measured a time delay of 5 to $10 \mathrm{~min}$ between ground signatures of activations of the outer and inner loops in the form of PBIs (oval north) and WEJ electrojet events at the oval equatorward boundary, respectively.

A detailed description of the DMSP F13 data obtained during the crossing of the oval at dusk at 10:40 UT, i.e., early in the interval of attenuated substorm activity, where we distinguish between the south $(\mathrm{S})$ and north $(\mathrm{N})$ sections of a double oval configuration, will be reported elsewhere.

Figure 8 shows geomagnetic indices AL and SYM-H for 18 August 2003. On this day we documented the presence of 


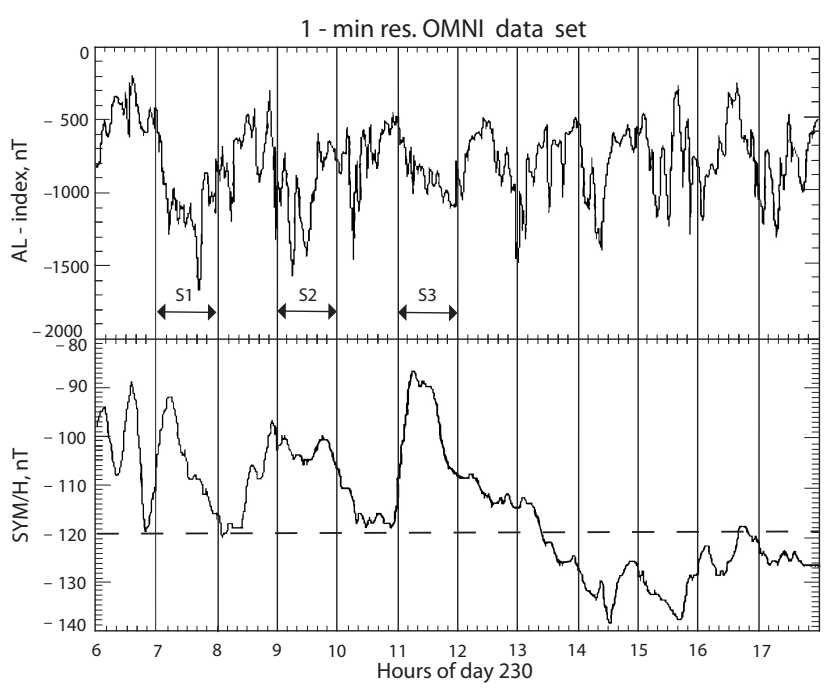

Figure 8. Geomagnetic indices AL (nT) and SYM-H (nT) for the interval 06:00-18:00 UT on 18 August 2003. Three sawtooth substorms during the interval 07:00-12:00 UT are marked S1, S2, and S3.

different substorm activities in the intervals 06:00-12:30 (I) and 12:30-18:00 UT (II). Interval I is characterized by three sawtooth substorms marked S1, S2, and S3 in Figure 8. These three substorms are observed in phases of SYM-H partial recovery (SYM-H $=-90$ to $-100 \mathrm{nT}$ ). Interval II consists of a different category of repetitive substorm activity which is related to BBFs and dipolarization fronts in the PS, as observed from 13:00 UT onwards by the spacecraft Geotail at $\mathrm{X}=-11 R_{\mathrm{E}}$ (data will be reported elsewhere). Contrary to the sawtooth events, this activity is accompanied by enhanced SYM-H deflection within -120 to $-140 \mathrm{nT}$. Figures 6 and 8 illustrate the presence of different variants of substorm activity related to different phases of ring current evolution as monitored by the SYM-H index.

\section{Discussion}

We address the roles of solar wind dynamic pressure and the ring current (SYM-H index) evolution for the activation of different states of M-I coupling during long intervals of continuously strong solar wind forcing. For this purpose we selected a case characterized by many hours of stable IP magnetic field conditions which included two abrupt changes (decrease and increase) of the solar wind dynamic pressure during an ICME passage at Earth on 25 July 2004. The two plasma discontinuities in the ICME (density drop and subsequent increase) were followed by distinct changes in the mode of M-I coupling (substorm activity). The density (dynamic pressure) drop recorded by the spacecraft Wind (located at $(261,5,18) R_{\mathrm{E}}$; GSE coordinates) at 09:15 UT led to a $3 \mathrm{~h}$ long interval of moderate dynamic pressure $(1 \mathrm{nPa})$ which was accompanied by repetitive events of moderate (quenched) substorm activity from $\sim 10: 10$ UT onwards. In this study we focus on the abrupt $P_{\text {dyn }}$ increase (from 1 to $5 \mathrm{nPa}$ ) recorded by Wind at 12:00 UT and the subsequent interval of extreme field line stretching at geostationary altitude (13:25-13:40 UT) which led to a major dipolarization accompanied by a stepwise poleward expansion of the westward electrojet at midnight. The phases of field stretching followed by dipolarization and electrojet expansion observed in the interval 13:25-14:00 UT compares well with the corresponding behavior observed during a sequence of sawtooth substorm events which occurred under similar IP conditions on 18 August 2003, as reported by Sandholt and Farrugia (2014).

I. The present case (25 July 2004; 13:00-14:00 UT) is characterized by the following observations. IP data (Wind satellite): (i) $P_{\text {dyn }}$ increase from 1 to $5 \mathrm{nPa}$ (12:00 UT at ACE), (ii) $M a$ increase from 2 to 5, (iii) $E_{\mathrm{KL}}$ decrease from 10 to $6 \mathrm{mV} \mathrm{m}^{-1}$, and (iv) minor (gradual) decrease in IMF clock angle $\left(135-120^{\circ}\right.$ ), (v) $B_{z} \approx-10 \mathrm{nT} ; B_{y} \approx-10 \mathrm{nT}$.

GOES-10 field-stretching and dipolarization events: (i) 30 min long stepwise field-stretching evolution during interval 13:00-13:30 UT: $B_{z}$ decreasing from 40 to $5 \mathrm{nT}$; intermittent episodes of $B_{x}$ increases from 60 to $105 \mathrm{nT}$ and $B_{\text {tot }}$ increases; and (ii) major dipolarization during the interval 13:40-14:00 UT: $B_{z}$ increase to $\sim 100 \mathrm{nT} ; B_{x}$ decrease; $B_{\text {tot }}$ increase followed by decrease.

This is to be compared with the mentioned sawtooth substorms.

II. The 18 August 2003 sawtooth cases (06:00-12:00 UT) are characterized by (Sandholt and Farrugia, 2014): IP data (ACE): (i) $P_{\text {dyn }}$ : stable level (3-4 nPa), (ii) $M a$ : stable level: $3-4$, (iii) $E_{\mathrm{KL}}: 8-10 \mathrm{mV} \mathrm{m}^{-1}$, and (iv) IMF: clock angle fluctuations within $135-180^{\circ}, B_{z} \sim-15 \mathrm{nT}$, $B_{y}=-5$ to $-10 \mathrm{nT}$.

GOES-10 field-stretching and dipolarization events: (i) $\sim 1 \mathrm{~h}$ long continuous field-stretching phases: $B_{z}$ decreasing from 60 to 5-10 nT, $B_{x}$ increasing from 40 to $100 \mathrm{nT}, B_{\text {tot }}$ increase; followed by (ii) major dipolarizations: $B_{z}$ increase from 10 to $80-100 \mathrm{nT}, B_{x}$ decrease from $\sim 100$ to $80 \mathrm{nT}$, and $B_{\text {tot }}$ decrease.

We note that after the $P_{\text {dyn }}$ increase on 25 July 2004 (12:00 UT on the Wind satellite), the IP conditions are very similar to those giving rise to sawtooth substorms on $18 \mathrm{Au}$ gust 2003 (Sandholt and Farrugia, 2014). The response of the nightside M-I system (during 13:00-14:00 UT) is also similar: a 30-60 min long phase of strong field line stretching leading to a major dipolarization with associated poleward expansion of the WEJ around midnight.

We conclude that the moderate plasma density (1$2 \mathrm{~cm}^{-3}$ ) and correspondingly moderate dynamic pressure $\left(P_{\mathrm{dyn}}=1 \mathrm{nPa}\right)$ observed during the interval $\sim 10: 10$ 13:00 UT on 25 July 2004 (Wind satellite data from 09:15 
to 12:00 UT) was not enough to create a sufficiently stretched magnetic field in the near-tail magnetosphere to initiate a major current disruption (CD) and a large-scale SCW, leading to major dipolarizations such as that observed during the later interval 13:40-14:00 UT. The $P_{\text {dyn }}$ increase detected by the Wind satellite at 12:00 UT, on the other hand, created the necessary field stretching which excited the $\mathrm{CD}$ process in the near-Earth PS. The preceding interval (10:10-13:00 UT at Earth) is dominated by brief field amplification and stretching events (GOES-10 data) which we relate to activations of the Bostrøm type II current system with associated eastward (IMAGE chain data) and westward (Alaska chain data) electrojet enhancements at the equatorward boundary of the auroral oval at dusk and post-midnight MLTs, respectively. In this state, the northern part of the auroral oval is dominated by PBIs (see Lyons et al., 1999 and Sandholt et al., 2002) and auroral streamers (Alaska chain data shown here and DMSP F13 data reported in Sandholt et al., 2014) which are taken to be signatures of multiple current wedgelets in the tail plasma sheet (see schematic illustration in Fig. 7).

This state of damped (quenched) substorm activity (absence of large-scale SCW expanding tailward; contrary to sawtooth events) was initiated by drops in IP plasma density and dynamic pressure (from 3 to $1 \mathrm{nPa}$ ) recorded by the Wind satellite at 09:15 UT. This observation proves the relationship with $P_{\mathrm{dyn}}$. Thus, with combined ground and satellite data, we distinguish between two fundamental modes of M-I coupling occurring under a similarly strong dayside merging rate $\left(E_{\mathrm{KL}}=6-12 \mathrm{mV} \mathrm{m}^{-1}\right)$, but different dynamic pressure. In fact, the dynamic pressure increase from 1 to $5 \mathrm{nPa}$ at 12:00 UT (Wind satellite), which led to field stretching (13:00-13:30 UT) and the major magnetic field dipolarization at 13:40 UT (GOES-10) and poleward expansions of the WEJ (full substorm), was accompanied by a drop in the geoeffective IP electric field $\left(E_{\mathrm{KL}}\right)$ from 10 to $6 \mathrm{mV} \mathrm{m}^{-1}$ associated with a decrease of the ICME magnetic field magnitude. The IMF clock angle increased only slightly. This emphasizes the role of $P_{\text {dyn }}$.

The attenuated substorm activity in the interval 10:3013:40 UT appears in the AL index as reduced deflection maxima, i.e., $\sim-1000 \mathrm{nT}$ vs. $\sim-2000 \mathrm{nT}$ (Fig. 6). The PCN index maxima are also reduced in this interval while the SYM$\mathrm{H}$ disturbance level is relatively high, fluctuating within the range of -130 to $-150 \mathrm{nT}$ (11:00-13:00 UT), increasing from $-100 \mathrm{nT}$ during the interval 09:00-10:00 UT. The same association between attenuated substorm activity (absence of large-scale sawtooth events) and enhanced SYM-H deflection (within $-120--140 \mathrm{nT}$ ) is seen on 18 August 2003 (after 12:30 UT), as documented in Fig. 8. Three sawtooth events during the interval 07:00-12:00 UT (marked S1, S2, and $\mathrm{S} 3$ in the figure) are accompanied by SYM-H relaxations at 07:00, 08:50, and 11:00 UT. These observation support the contention that the attenuated substorm activity is associated with multiple wedgelets (BBFs/DFs) rather than a large-scale
SCW. Sawtooth events are, on the other hand, characterized by a large-scale SCW (Sandholt and Farrugia, 2014).

Our result of the substorm triggered by a solar wind dynamic pressure enhancement is consistent with the previous results of Petrinec and Russell (1996) and Shue and Kamide (1998) finding that solar wind density variations during periods of southward IMF can trigger substorms. Likewise, there is evidence for the triggering of tail reconnection by sudden enhancements in solar wind dynamic pressure (see, e.g., Milan et al. (2007) and references therein). We find that the enhancement of $P_{\text {dyn }}$ in our case led to extreme field line stretching $\left(B_{z}=5 \mathrm{nT} ; B_{x}=100 \mathrm{nT}\right)$ in the near-Earth PS (GOES-10 data at 13:40 UT) which was followed by CD and a large-scale SCW (major dipolarization) with associated stepwise poleward expansion of the WEJ in the northern part of the oval at night (Alaska data in the interval 13:4014:00 UT).

Karlsson et al. (2000) found that a solar wind pressure pulse of only $2 \mathrm{nPa}$ can trigger a substorm at the time of a partially completed growth phase. In our case, the full electrojet expansion was triggered after a $30 \mathrm{~min}$ long phase (13:0013:30 UT) of field line stretching, when $B_{z}$ decreased from 40 to $5 \mathrm{nT}$ ( $B_{x}$ increase from 60 to $100 \mathrm{nT}$ ). We note that this is somewhat shorter than the corresponding $\sim 60 \mathrm{~min}$ long phases of field stretching before dipolarizations observed during the conditions of continuously high (3-4 nPa) dynamic pressure in the case of the sawtooth substorms on 18 August 2003 (Sandholt and Farrugia, 2014). Concerning the mechanism for the relation between solar wind dynamic pressure and the stretching of the magnetic field in the nearEarth PS, we refer to Karlsson et al. (2000) and Lockwood (2013).

\section{Summary}

By combining magnetosphere and ionosphere observations, we document transitions between two different variants of substorm activity which occurred during a long interval of strong forcing of the magnetosphere during the ICME passage on 25 July 2004. Magnetic field and energetic electron flux data near the PS-to-ring current boundary, obtained from satellite GOES-10, are combined with auroral electrojet observations in the northern and southern sections of the oval at midnight and dusk, as well as the AL and SYM-H indices. A $3 \mathrm{~h}$ long interval of damped WEJ activity under strong storm conditions (SYM-H $=-120$ to $-160 \mathrm{nT}$ ) is sandwiched between two intervals dominated by strong WEJ activity covering a wide latitude range (Alaska chain data) and SYM-H relaxation to lower levels of disturbance $(>-120 \mathrm{nT})$. The attenuated substorm activity in the interval of reduced $P_{\text {dyn }}$ $(\approx 1 \mathrm{nPa})$ is characterized by the absence of WEJ expansions from lower to higher latitudes around midnight (Alaska). Instead, the oval north regime consists of a series of brief magnetic deflections related to PBIs (Fig. 4). The attenuated WEJ events in the oval south regime at midnight are con- 
jugate to magnetic perturbations and energetic electron flux dropouts at geostationary altitude which we attribute to activations of a Bostrøm type II (meridional) current system. This WEJ activity in oval south around midnight (10:0013:30 UT) is accompanied by a very strong EEJ activity at dusk (IMAGE data). The latter EEJ events, and the strong SYM-H deflection, are manifestations of plasma intrusion events (BBFs) towards the PRC and associated M-I coupling involving Bostrøm type II (inner loop) activations. This inference is supported by BBFs/DFs observed at $\mathrm{X}=-11 R_{\mathrm{E}}$ (Geotail data) and subsequent activations of a Bostrøm type II current system at $\mathrm{X}=-5 R_{\mathrm{E}}$ (GOES-10 data), leading to EEJ events at dusk, as documented during a similar ICME case (Sandholt et al., 2014). Thus, a specific M-I coupling between the PRC and the oval south regime, triggered by plasma intrusion events (DFs/BBFs), is found to be characteristic of this variant of substorm activity, with its manifestations at dusk (EEJ) and midnight (WEJ).

We conclude that the two-loop M-I current system involving the disrupted (diverted) cross-tail current (outer branch) and the PRC (inner branch) appears in two different states leading to different variants of repetitive electrojet activity in the north and south sections of the auroral oval at dusk and midnight. In the interval of reduced dynamic pressure, BBFs/streamers in oval north are followed by EEJ/WEJ events in the south section of the auroral oval. The strong M-I coupling (via BII current systems) to the EEJ in oval south at dusk (see Sandholt et al., 2014 and Fig. 5) and to the WEJ in oval south at midnight (inner loops) appears as a series of electrojet events recurring at 20-40 min intervals combined with enhanced SYM-H deflections in the range of -130 to $-150 \mathrm{nT}(11: 00-13: 30 \mathrm{UT})$. The transition back to higher dynamic pressure is followed by extreme magnetic field stretching $\left(B_{z}=5 \mathrm{nT} ; B_{x}=100 \mathrm{nT}\right)$ at GOES-10 (13:2513:40 UT), and SYM-H relaxation (13:20-13:40 UT).

In this case study, we distinguish between two fundamental modes of M-I coupling and we identify clear IP discontinuities (plasma density and dynamic pressure changes) as the external sources of transitions between the two states of the magnetosphere. Thus, this study emphasizes the important role of the IP parameters plasma density and dynamic pressure in the geoeffectiveness of ICMEs and the appearance of different variants of substorm activity. The variant representing low $P_{\text {dyn }}$ conditions is characterized by (i) attenuated WEJ activity around midnight (also reflected in reduced AL disturbances), (ii) strong EEJ events at dusk, (iii) attenuated polar cap convection events (reduced PCN index peaks), and (iv) enhanced SYM-H deflection. These ionospheric signatures may correspond to a fragmented SCW (wedgelets), with associated plasma intrusions to the near-Earth PS (see SYM-H events), giving rise to effective M-I coupling from the PRC to the oval south regimes at dusk and midnight via Bostrøm type II current systems (Fig. 7).

Observations in the Harang discontinuity region (DMSP F15 data in the 19:00-20:00 MLT sector; not shown here) illustrate a moderate (attenuated) oval north activity extending to $69^{\circ}$ MLAT (11:18 UT; center time of one M-I coupling event; see Fig. 5). This is in contrast to the larger WEJ expansion, extending to $74^{\circ}$ MLAT at 14:44 UT, identified by F15 data during a large AL deflection event (Fig. 6) which took place when $P_{\text {dyn }}$ had returned to higher values. These F15 observations confirm the distinction between attenuated and full-size WEJ expansions corresponding to the different $P_{\text {dyn }}$ conditions reported in this study.

Acknowledgements. This work was supported in part by NASA Grants NNX10AQ29G and NNX13AP39G. We thank the institutions for operating the IMAGE (FMI, Finland and Troms $\varnothing$ Geophysical Observatory, Norway) and Alaska chain (University of Alaska, Fairbanks) ground magnetometers used in this study. Magnetic indices AL and SYM-H were obtained from omniweb.gsfc.nasa.gov.

Topical Editor E. Roussos thanks A. Anastasiadis and Y. Andalsvik for help in evaluating this paper.

\section{References}

Akasofu, S. I.: The relationship between the magnetosphere and magnetospheric/auroral substorms, Ann. Geophys., 31, 387-394, doi:10.5194/angeo-31-387-2013, 2013.

Baumjohann, W., Paschmann, G., and Luhr, H.: Characteristics of high-speed flows in the plasma sheet, J. Geophys. Res., 95, 38013809, 1990.

Birn, J. and Hesse, M.: The substorm current wedge: Further insights from MHD simulations, J. Geophys. Res., 119, doi:10.1002/2014JA019863, 3503-3513, 2014.

Bostrøm, R.: A model of the auroral electrojets, J. Geophys. Res., 69, 4983-4999, 1964.

Bostrøm, R.: Currents in the ionosphere and magnetosphere, in: The Birkeland Symposium on Aurora and Magnetic Storms, edited by: Egeland, A. and Holtet J., C.N.R.S., 445-458, Sandefjord, Norway, 1967.

Bostrøm, R.: Current systems in the magnetosphere and ionosphere, in: Radar Probing of the Auroral Plasma, edited by: Brekke, A., Universitetsforlaget, Troms $\emptyset$ - Oslo - Bergen, Norway, 257-284, 1977.

Henderson, M. G., Skoug, R., Donovan, E., Thomsen, M. F., Reeves, G. D., Denton, M. H., Singer, H. J., McPherron, R. L., Mende, S. B., Immel, M. F., Sigwarth, J. B., and Frank, L. A.: Substorms during the 10-11 August 2000 sawtooth event, J. Geophys. Res., 111, A06206, doi:10.1029/2005JA011366, 2006.

Kamide, Y., Baumjohann, W., Daglis, I. A., Gonzales, W. D., Grande, M., Joselyn, J. A., McPherron, R. L., Phillips, L., Reeves, E. G. D., Rostoker, G., Sharma, A. S., Singer, H. J., Tsurutani, B. T., and Vasyliunas, V. M.: Current understanding of magnetic storms: Storm - substorm relationship, J. Geophys. Res., 103, 17705-17728, 1998.

Kan, J. R. and Lee, L. C.: Energy coupling function and solar windmagnetosphere dynamo, Geophys. Res. Lett., 6, 577-580, 1979.

Karlsson, S. B. P., Opgenoorth, H. J., Eglitis, P., Kauristie, K., Syrjasuo, M., Pulkkinen, T., Lockwood, M., Nakamura, R., Reeves, 
G., and Romanov, S.: Solar wind control of magnetospheric energy content: Substorm quenching and multiple onsets, J. Geophys. Res., 105, 5335-5356, 2000.

Lockwood, M.: Reconstruction and prediction of variations in the open solar magnetic flux and interplanetary conditions, Living Rev. Solar Phys., 10, 1-88, doi:10.12942/lrsp-2013-4, 2013.

Lyons, L., Lee, D.-Y., Wang, C.-P., and Mende, S.: Global auroral response to abrupt solar wind changes: Dynamic pressure,substorm, and null events, J. Geophys. Res., 110, A08208, doi:10.1029/2005JA011089, 2005.

Lyons, L. R., Nagai, T., Blanchard, G. T., Samson, J. C., Yamamoto, T., Mukai, T., Nishida, A., and Kokubun, S.: Association between Geotail plasma flows and auroral poleward boundary intensifications observed by CANOPUS photometers, J. Geophys. Res., 104, 4485-4500, 1999.

McPherron, R. L., Russell, C. T., and Aubry, M. A.: Satellite studies of magnetospheric substorms on August 15, 1968, 9, phenomenological model for substorms, J. Geophys. Res., 78, 31313149, 1973.

Milan, S., Provan, G., and Hubert, B.: Magnetic flux transport in the Dungey cycle: A survey of dayside and nightside reconnection rates, J. Geophys. Res., 112, A01209, doi:10.1029/2006JA011642, 2007.

Nakamura, R., Baumjohann, W., Klecker, B., Bogdanova, Y., Balogh, A., Reme, H., Bosqued, J. M., Dandouras, I., Sauvaud, J. A., Glassmeier, K.-H., Kistler, L., Mouikis, C. Zhang, T. L., Eichelberger, H., and Runov, A.: Motion of the dipolarization front during a flow burst event observed by Cluster, Geophys. Res. Lett., 29, 1942, doi:10.1029/2002GL015763, 2002.

Noah, M. A. and Burke, W. J.: Magnetospheric conditions for sawtooth event development, J. Geophys. Res., 119, 2494-2511, doi:10.1002/2013JA019573, 2014.

Petrinec, S. M. and Russell, C. T.: Near-earth magnetotail shape and size determined from the magnetopause flaring angle, J. Geophys. Res., 101, 137-152, doi:10.1029/95JA02834, 1996.

Pulkkinen, T. I., Palmroth, M., Tanskanen, E. I., Ganushkina, N. Y., Shukhtina, M. A., and Dimitrieva, N. P.: Solar windmagnetosphere coupling: A review of recent results, J. Atm. Sol. Terr. Phys., 69, 256-264, 2007.
Runov, A., Angelopoulos, V., Zhou, X.-J., Li, S., Plaschke, F., and Bonnell, J.: A THEMIS multicase study of dipolarization fronts in the magnetotail plasma sheet, J. Geophys. Res., 116, A05216, doi:10.1029/2010JA016316, 2011.

Sandholt, P. E. and Farrugia, C. J.: Aspects of magnetosphereionosphere coupling in sawtooth substorms: a case study, Ann. Geophys., 32, 1277-1291, doi:10.5194/angeo-32-1277-2014, 2014.

Sandholt, P. E., Farrugia, C. J., Lester, M., Cowley, S. W. H., Milan, S., Denig, W. F., Lybekk, B., Trondsen, E., and Vorobjev, V.: Multistage substorm expansion: Auroral dynamics in relation to plasma sheet particle injection, precipitation, and plasma convection, J. Geophys. Res., 107, 1342, doi:10.1029/2001JA900116, 2002.

Sandholt, P. E., Farrugia, C. J., and Denig, W. F.: M-I coupling across the auroral oval at dusk and midnight: repetitive substorm activity driven by interplanetary coronal mass ejections (CMEs), Ann. Geophys., 32, 333-351, doi:10.5194/angeo-32-333-2014, 2014.

Sergeev, V. A., Angelopoulos, V., and Nakamura, R.: Recent advances in understanding substorm dynamics, Geophys. Res. Lett., 39, L0511, doi:10.1029/2012GL050859, 2012.

Sergeev, V. A., Nikolaev, A. V., Tsyganenko, N. A., Angelopoulos, V., Runov, A. V., Singer, H. J., and Yang, J.: Testing a two-loop pattern of the substorm current wedge, J. Geophys. Res., 119, 947-963, doi:10.1002/2013JA019629, 2014.

Shue, J.-H. and Kamide, Y.: Effects of solar wind density on the westward electrojet, in: Proceedings of the Fourth International Conference on Substorms, Lake Hamana, Japan, 9-13 March 1998, p. 667, Terra Sci., Tokyo, Japan, 1998.

Tsyganenko, N. A.: Data-based modelling of the Earth's dynamic magnetosphere: a review, Ann. Geophys., 31, 1745-1772, doi:10.5194/angeo-31-1745-2013, 2013.

Yang, J., Toffoletto, F. R., Wolf, R. A., Sazykin, S., Ontiveros, P. A., and Weygand, J. M.: Large-scale current systems and ground magnetic disturbance during deep substorm injections, J. Geophys. Res., 117, A04223, doi:10.1029/2011JA017415, 2012.

Yasuhara, F., Kamide, Y., and Akasofu, S.-I.: Field-aligned and ionospheric currents, Planet. Space Sci., 23, 1355-1368, 1975. 